\title{
Model Analysis and Optimization of BIM Technology in High-rise Shear Wall Residential Structure
}

\author{
Liangli Xiao ${ }^{1, a}$, Yan Liu ${ }^{1}$, Zhuang Du ${ }^{1}$, Zhao Yang ${ }^{1}$, Kai Xu ${ }^{1}$ \\ ${ }^{1}$ Institute of Urban Construction, Wuhan University of Science and Technology, Wuhan 430065, China
}

\begin{abstract}
This study combines specific high-rise shear wall residential projects with the Revit to demonstrate BIM application processes. The use of R-Star CAD may help to realize the link barrier of the building information model and the structural analysis software PKPM. Sequentially, the information supplement of the structural analysis model is completed by extracting the structural information with the Revit secondary development. By the collaborative design platform based on BIM technology, the paper examines the collision check of structural model, conducts collision analysis on other professional models and modifies the design scheme for conflict points. After the statistics of material usage, an optimized design is proposed. The findings of this paper could contribute to provide some reference for the specific application of BIM in structural design and realize the application of BIM technology in the process of building structure design.
\end{abstract}

Keywords: BIM technology; Structural design; Structural analysis model; Collaborative design.

\section{Introduction}

With the rapid development of BIM technology and the continuous improvement of tool software based on BIM technology, BIM technology has gradually been recognized and applied by Chinese engineering circles. At present, the depth and breadth of architects accepting and applying BIM technology is far greater than that of structural engineers. There are still many technical problems and obstacles in the structural design of BIM technology in engineering applications to be studied and solved. For example, structural professional and construction, electromechanical and other related majors implement BIM-based collaborative design and two-way links between structural information models and structural analysis software. Only by gradually solving the problems in these applications, each major can follow up and develop the application of BIM technology at the same time, so that the BIM design of the entire design process can be truly realized, and the value brought by BIM to the field of architectural design can be fully displayed, thereby improving the quality and efficiency of architectural design [1,2].

This paper focuses on the difficulties and obstacles of BIM technology in architectural design application. From the perspective of structural specialty, combined with the specific engineering, the design method based on BIM technology is used to complete the design and optimization of the project. Use the Revit to build a building structure information model for a shear wall high-rise residential project. Implement a two-way linking of BIM physical models and structural analysis models by software secondary development and R-star CAD. Calculated and analyzed the BIM structural model or returned the analysis results. Collision analysis of models using BIM technology collaborative design platform, then modify the design. And combined with the rich parameter information and powerful database of BIM model, the statistical calculation of materials is carried out. More economical and optimized designs are obtained from the perspective of saving material costs. In the structural design, the application diagram of BIM is shown in Figure 1.

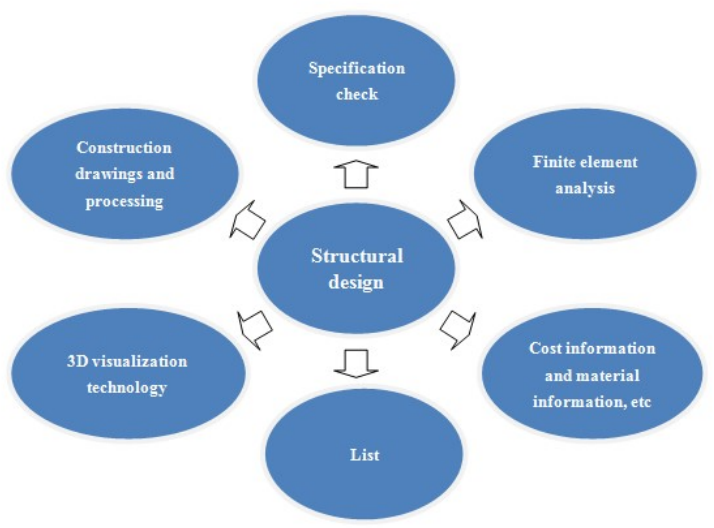

Figure 1. Application diagram of BIM in structural design.

${ }^{\mathrm{a}}$ Corresponding author: xiaoliangli@wust.edu.cn 


\section{Project overview}

This project is a 34-storey high-rise residential building in Wuhan with a large underground garage. It adopts all floor-standing shear wall structure and has a design life of 50 years. The building length is 45 meters and the width is 17.7 meters. 2.9 meters, the main structure height is 98.6 meters. The building is shown in Figure 2 and Figure 3.

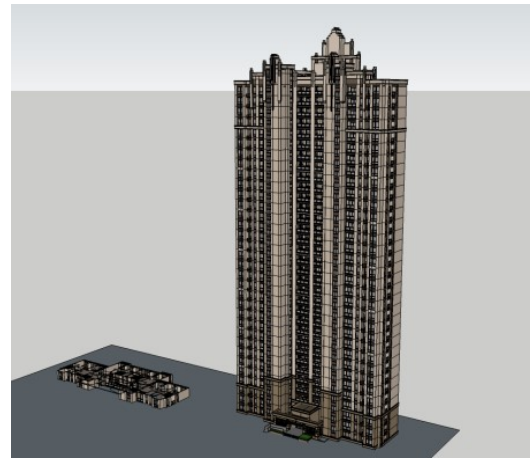

Figure 2. Model picture of the high-rise residential building.

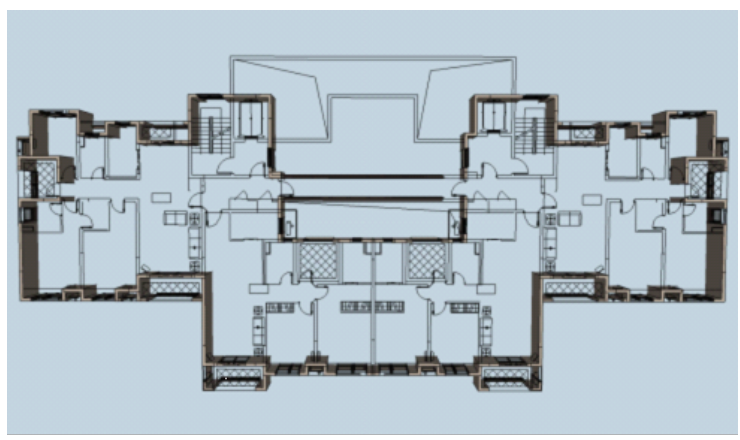

Figure 3. Floor plan of the high-rise residential building.

It mainly analyzes the overall index of the project with positive and negative zero and above structure. The structural embedded end is set as the basement roof, and the large basement and foundation part are not discussed. Some preliminary design structure technical measures are as follows.

\subsection{Natural conditions}

Basic wind pressure: $0.35 \mathrm{kN} / \mathrm{m}^{2}$;

Ground roughness class: $\mathrm{B}$;

Basic snow pressure: $0.45 \mathrm{kN} / \mathrm{m}^{2}$;

Snow load quasi-permanent value partition: II

\subsection{Fortification standards (as shown in Table 1)}

Table 1. This project fortification standard table.

\begin{tabular}{|c|c|c|}
\hline $\begin{array}{c}\text { Earthquake } \\
\text { fortification } \\
\text { intensity }\end{array}$ & $\begin{array}{c}\text { Design of } \\
\text { earthquake group }\end{array}$ & $\begin{array}{c}\text { Ground motion } \\
\text { acceleration }\end{array}$ \\
\hline 6 & first group & $0.05 \mathrm{~g}$ \\
\hline $\begin{array}{c}\text { Site } \\
\text { classification }\end{array}$ & $\begin{array}{c}\text { Characteristic } \\
\text { period value of the } \\
\text { seismic design } \\
\text { response spectrum }\end{array}$ & $\begin{array}{c}\text { The maximum } \\
\text { horizontal seismic } \\
\text { influence } \\
\text { coefficient }\end{array}$ \\
\hline II & 0.35 & 0.04 \\
\hline
\end{tabular}

\subsection{Main materials}

i) Concrete strength grade: C35 or more for columns and shear walls, C30 for beam plates;

ii) Reinforcement: beam bars HRB400; column and shear wall bars HRB400; stirrup for beams, beams, shear wall edge members HPB235; steel bar stress for ordinary floor slab, roof slab HRB400; distributing bars for plate HPB235.

\section{Establishing BIM model}

Based on the building information technology standard CBIMS, the Revit is used to establish the BIM structural model [3]. This project is the same standard layer except for the first floor and the roof layer. Figure 4 shows the initial the Revit structure model. The structural arrangement can be viewed stereoscopically from various angles of the space by the 3D model.
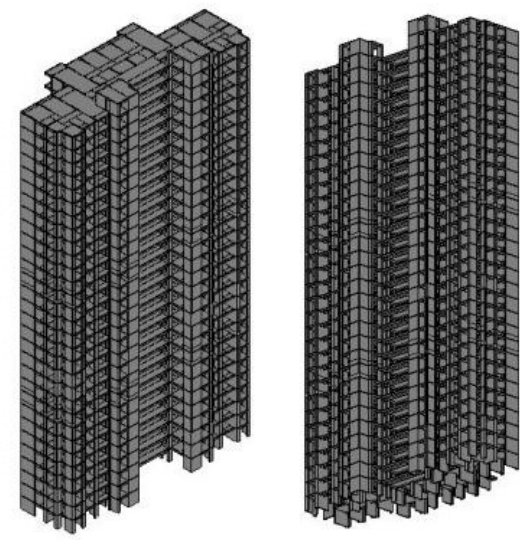

Figure 4. The Revit structure model diagram.

At the same time, it is also possible to perform 2D drawing output on the model by selecting the view visibility. The structural plan is the basic drawing used to represent the structure, and all other types of drawings need to be designed based on the plan. Therefore, when using BIM technology to reflect the structure of the process, the expression of the floor plan must be accurate and detailed, in order to create conditions to complete other drawings[4]. However, the hardware limitations were received in this project, and the fine input of information was not fully implemented, so the results are only for reference.

\section{Model analysis}

Structural design not only needs to represent the physical model of the spatial component, but also the structural analysis model used to construct the structural analysis, such as component boundary conditions, structural loads, beam-slab analysis models, etc. The Revit does not have structural analysis capabilities. To achieve structural analysis needs to be completed by a combination with third-party structural analysis software. This model still uses PKPM's SATWE program for structural analysis. And the R-star CAD software is used to realize the 
bidirectional mutual conversion between the Revit and the PKPM model data.

\subsection{The Revit structure analysis model parameter settings}

Before performing structural analysis with PKPM, some structural parameters need to be set, including: symbol representation setting, load case, load combination, analysis model setting and structural boundary condition. Figure 5 shows the physical model of the structure and Figure 6 shows the structural analysis model.

The physical model is used to provide the user with a solid model for guiding construction, material statistics, investment budget, etc. The analytical models are used for structural analysis and calculations to provide the structural information needed for structural calculations.
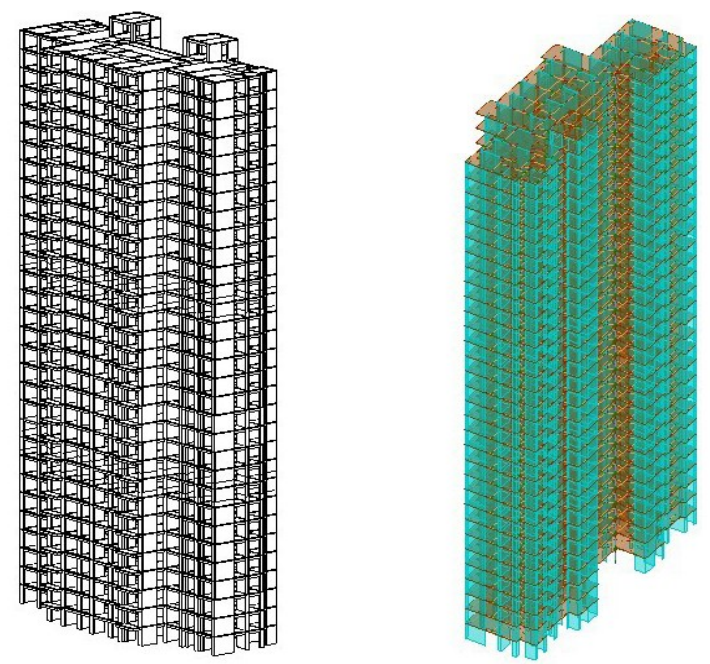

Figure 5. Physical model of the Revit (left).

Figure 6. Analysis model of the Revit(right).

\subsection{Realize the interaction between the Revit and the PKPM models by R-star CAD}

When trying to directly connect the Revit and the PKPM2010, it was found that the data loss was serious, leaving only the grid and part of the shear wall. Therefore, the R-star CAD is used to achieve the docking exchange between the two.

\subsection{Extraction and supplement of structural information}

Based on the secondary development of the Revit, it is convenient to extract the required structural calculation information from the model. After the structural information model is imported into the PKPM by the RStar CAD, it can also supplement and correct the structural analysis model in the PKPM to complete the data conversion more accurately. The algorithm for designing the structural model information algorithm is shown in Figure $7[5,6]$.

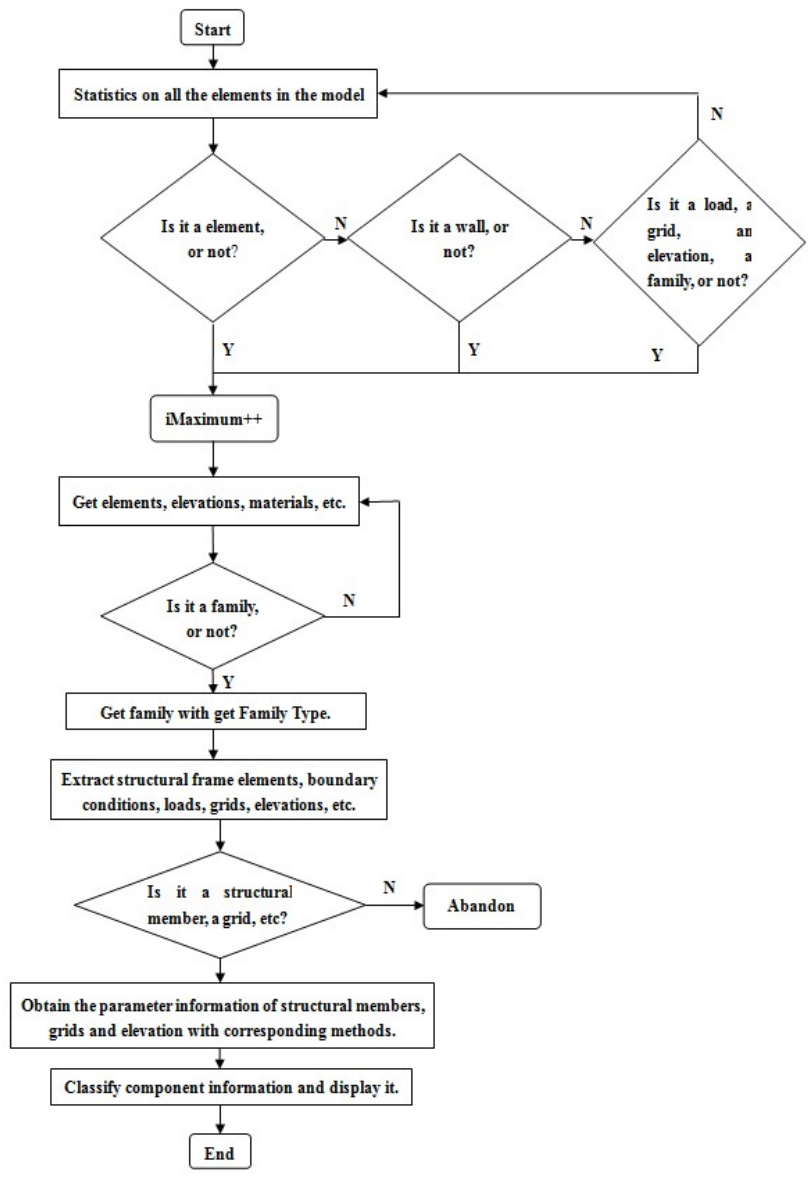

Figure 7. Flow chart of algorithm design for extracting structural member information.

\subsection{Structural analysis results}

The structural analysis model is imported into the PKPM, and the extracted model information is supplemented to generate a whole-floor model for structural analysis. The models in PM are shown in Figure 8 and Figure 9.

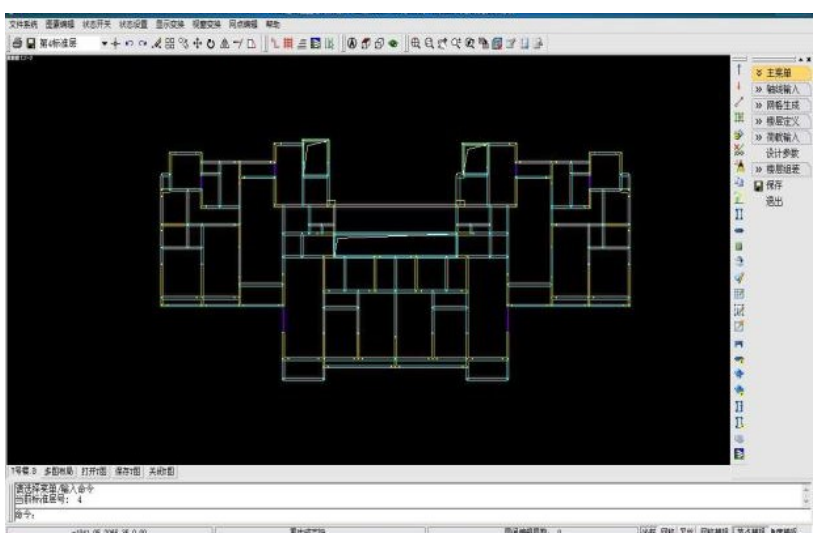

Figure 8. Plane standard layer plan in PM. 


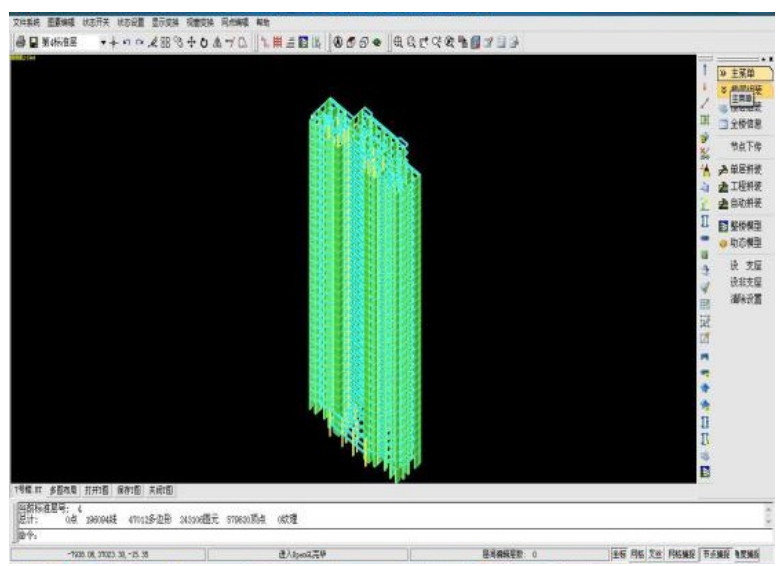

Figure 9. Model of the whole building in PM.

The results of the analysis results are basically similar to those of the traditional method modeling analysis, and there is not much deviation, indicating that the docking of the model is still true and effective.

i) The overall vibration diagram of the structural space, the displacement and cycle ratio of the structure are in compliance with the specifications. Figure 10 shows the structural space translation diagram and Figure 11 shows the structural space torsion diagram.

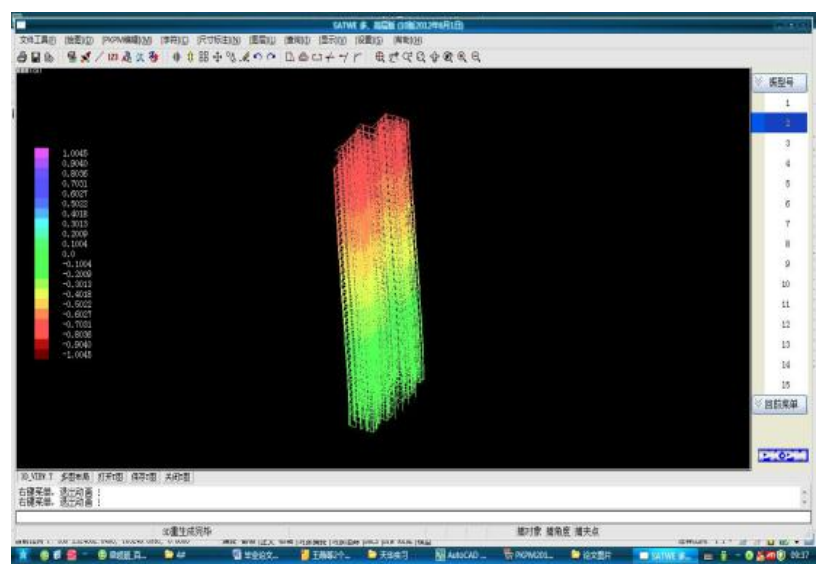

Figure 10. Structure space translational vibration pattern.

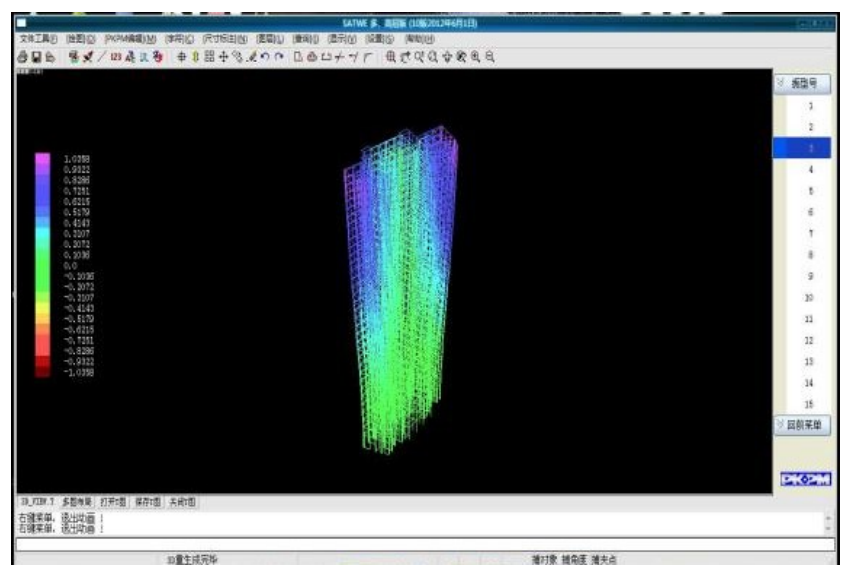

Figure 11. Structural space torsional vibration pattern.

ii) The part of the SATWE calculation book is taken as an example to illustrate that the overall analysis index of the structure meets the specification requirements. iii) The calculation diagram of the reinforcement of concrete members is represented by the tenth layer with the largest reinforcement.

\section{Project optimization design based on BIM technology}

The building model based on BIM technology is a model that contains rich building information. In practice, we can get a lot of building information from design. Therefore, the design is optimized in many aspects, such as making it safer, more economical and more comfortable. Here we cut in from the following two aspects to optimize the structural design.

\subsection{Structural scheme modification based on collision analysis results}

BIM-based design allows for the integration of all professional models. A project file in the Revit can link multiple the Revit models and then conduct a thorough and thorough collision check between the disciplines themselves and each other. Since the model is built to the true dimensions, some of the deeper problems that cannot be revealed in traditional drawings can be clearly and thoroughly displayed in the model. In this way, the precision and the depth of the drawing in the design are greatly improved, and the drawing mismatch caused by the communication obstacles of various professional designers can be avoided in many designs.

Many problems were discovered by the conflict report of the collision results. For example, the beam width between the electric wells is too large, which affects the size of the electric well. And the setting of the upper shear wall does not consider the opening requirements of the first floor entrance hall. In response to these problems, the location of the primitive can be automatically and quickly located according to the primitive ID generated by the report, and the conflicting components can be directly modified. After the modification is completed, the refresh can be re-tested again, the resolved conflicts will no longer be displayed and the modified results can be reflected on the collaborative design platform and associated with the relevant professional models. In this way, each conflict is checked, modified, and detected one by one, which is convenient and accurate, avoids the omission of human communication inspection, reduces communication procedures and improves design efficiency.

\subsection{Optimization selection based on material statistical results}

For the established structural model, the Revit can use the "material extraction" function to calculate the material usage of each object in the project. An example of automatically generating concrete usage. Figure 12 is a partial interception of the generated concrete usage statistics. You can also fill in the manufacturer and cost information in the material of the Administration tab, as shown in Figure 13, for a preliminary cost budget. 


\begin{tabular}{|c|c|c|c|c|}
\hline \multicolumn{5}{|c|}{ Concrete consunption } \\
\hline Fanily & Family and type & Ilaterial: Iane & llaterial: Volune & Ilaterial: Cost \\
\hline Floor & Floor: on-site pouring & Concrete - sand / water & 18.16 cubic neters & \\
\hline Floor & Floor: on-site pouring & Concrete - sand / water & 18.16 cubic neters & \\
\hline Floor & Floon: onsite pouring & Concrete - sand / water & 18.16 cubic neters & \\
\hline Floor & Floor: on-site pouring & Concrete - sand / water & 18.16 cubic neters & \\
\hline Floor & Floon: on-site pouring & Concrete - sand / water & 18.16 cubic neters & \\
\hline Floor & Floor: onsite pouring & Concrete - sand / water & 18.16 cubic neters & \\
\hline Floor & Floon: on-site pouring & Concrete - sond / water & 18.16 cubic neters & \\
\hline Floor & Floor: onsite pouring & Concrete - sand / water & 18.16 cubic neters & \\
\hline Floor & Floor: onrsite pouring & Concrete - sand / rater & 18.16 cubic neters & \\
\hline Floor & Floor: onsite pouring & Concrete - sand / rater & 18.16 cubic neters & \\
\hline Floor & Floon: on-site pouring & Concrete - sand / vater & 18.16 cubic neters & \\
\hline Floor & Floor: on-site pouring & Concrete - sand / water & 1.74 cubic neters & \\
\hline \multicolumn{5}{|c|}{ oncrete - sand / cenent leveling: 26} \\
\hline Concrete - rectangular & Concrete-rectangular bezn & Concrete: on-site pouring & 1.11 cubic neters & \\
\hline Concrete - rectangular & Concrete-rectangular bean & Concrete: on-site pouring & L.11 cubic neters & \\
\hline Concrete - rectangular & Concrete-rectangular bean & Concrete: on-site pouring & 0.08 cubic neters & \\
\hline Concrete - rectangular & Concrete-rectangular bean & Concrete: on-site pouring & 0.12 cubic neters & \\
\hline Concrete - rectangular & Concrete-rectangular bean & Concrete: on-site pouring & 0.19 cubic neters & \\
\hline Concrete - rectangular & Concrete-rectangyllar bean & Concrete: on-site pouring & 0.18 cubic neters & \\
\hline Concrete - rectangular & Concrete--rectangyular bean & Concrete: on-site pouring & 0.13 subic neters & \\
\hline Concrete - rectangular & Concretete-rectangular bean & Concrete: on-site pouring & 0.17 cubic neters & \\
\hline Concrete - rectangular & Concrete-rect tangular bean & Concrete: on-site pouring & 0.22 subic neters & \\
\hline Concrete - rectangular & Concrete-rect tngyular bezn & Concrete: or-site pouring & 0.11 cubic neters & \\
\hline Concrete - rectangular & Concrete-rect tngyular bezn & Concrete: on-site pouring & 0.20 cubic neters & \\
\hline Concrete - rectangular & Concrete-rectangular bezn & Concrete: on-site pouring & 0.27 cubic neters & \\
\hline Concrete - rectangular & Concrete-rectangular bean & Concrete: on-site pouring & 0.17 cubic neters & \\
\hline Concrete - rectangular & Concrete-rectangular bean & Concrete: on-site pouring & 0.26 cubic neters & \\
\hline
\end{tabular}

Figure 12. Part of the concrete usage map.

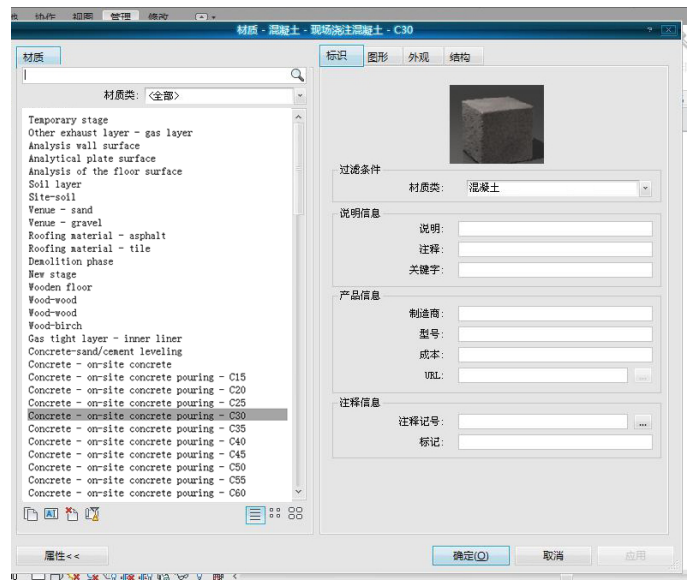

Figure 13. The Revit material information management interface.

After the optimization of the reinforcement, the final design is determined and the construction drawing is drawn to guide the construction. Due to the large size of the drawing, only a partial enlargement example is provided here. Figure 14 is a partial enlarged view of the reinforcement of a layer of beams, and Figure 15 is a partial enlargement of the reinforcement of the edge members of the shear wall.

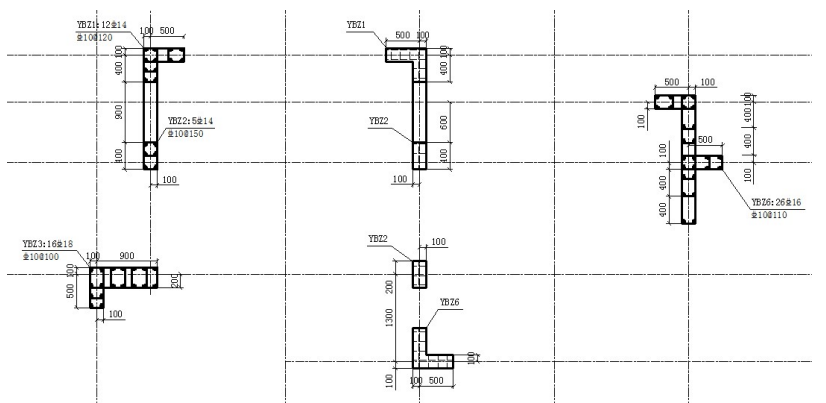

Figure 14. Beam reinforcement construction drawing partial enlargement.

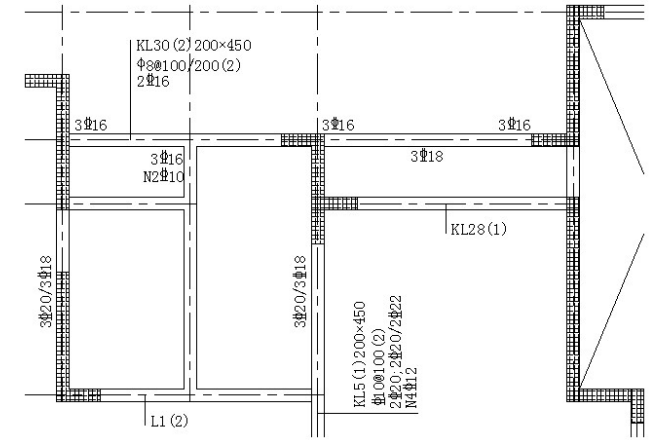

Figure 15. Restricted edge member reinforcement diagram partial enlargement.

Although this function of the BIM can not completely determine the cost of engineering, it provides another perspective for designers to design and makes the design more practical and economical.

\section{Conclusions}

This study combines the specific engineering practice to demonstrate the application process of BIM, aims at solving the data conversion problem between the Revit and the PKPM which is structural analysis software, trys to solve the link barrier of structural physical model and analysis model based on BIM technology and conducts collision analysis of various professional models to provide reference for the practice of BIM technology. By counting the amount of material used, the optimized design is presented, which reflects the economic benefits of BIM technology in building structure design. The findings of this paper could contribute to attract more people to pay attention to BIM technology, promote related research or application and bring out the true value of BIM.

\section{References}

1. L. Ustinovičius, A. Puzinas, J. Starynina, M. Vaišnoras, O. Černiavskaja, R. Kontrimovičius, Challenges of BIM technology application in project planning, Engineering Management in Production and Services, 10, 15-28(2018)

2. M. Uhm, G. Lee, B. Jeon, An analysis of BIM jobs and competencies based on the use of terms in the industry, Automation in Construction, 81, 67-98(2017)

3. K. Araszkiewicz, Green BIM Concept - Scandinavian Inspirations, Archives of Civil Engineering, 62, 99110(2016)

4. X. Brioso, D. Murguia, A. Urbina, Comparing three scheduling methods using BIM models in the Last Planner System, Organization, Technology and Management in Construction: an International Journal, 9, 1604-1614(2017)

5. Ang Zhao, Application of BIM Technology in Computer Aided Architectural Design, 7-9(Master's thesis of Chongqing University, 2006)

6. A. Glema, Building Information Modeling BIM Level of Digital Construction, Archives of Civil Engineering, 63, 39-51(2017) 